\title{
Anotaciones sobre el fetiche cultural y el cine ${ }^{1}$
}

\section{Juan David Cárdenas²}

Recibido: 2013-12-16

Enviado a pares: 2013-12-17
Aprobado por pares: 2014-01-29

Aceptado: 2014-03-28

DOI: 10.5294/pacla.2014.17.3.3

Para citar este artículo / To reference this article / Para citar este artigo

Cárdenas, J.D. Septiembre 2014. Anotaciones sobre el fetiche cultural y el cine. Palabra

Clave 17 (3), 619-644. DOI: 10.5294/pacla.2014.17.3.3

\section{Resumen}

Sobre los fenómenos culturales, sea que se trate de productos de la industria cultural o de actividades de gestión cultural, recae una serie de imaginarios. Dado esto, ellos se comportan como fetiches al modo de la mercancía. El siguiente artículo se propone revisar este carácter de fetiche de los objetos culturales y particularmente del cine, atendiendo en detalle algunos de los argumentos que Adorno y Horkheimer exponen sobre la industria cultural. De este modo, además de precisar algunos aspectos del pensamiento de los teóricos de Frankfurt, nos proponemos revisar la naturaleza profunda del cine como objeto cultural.

\section{Palabras clave}

Cultura, Industria cultural, Gestión cultural, Producción cinematográfica, cine (Fuente: Tesauro de la Unesco).

1 El presente artículo es resultado del proyecto de investigación "Cine, gestión e industria cultural y política", llevado a cabo durante el año 2013, dentro del grupo de investigación Pensamiento Artístico y Comunicación, de la Escuela de la Imagen de la Corporación Universitaria Unitec.

2 Pontificia Universidad Javeriana, Colombia. juandavidcardenas@hotmail.com 


\title{
Notes on the Cultural Fetish and Cinema
}

\begin{abstract}
Cultural phenomena, be they products of the cultural industry or of cultural management activities, evoke a series of imaginaries. As such, they act as fetishes in the form of merchandise. The article revisits this fetishism of cultural objects, cinema in particularly, looking in detail at some of the arguments raised by Adorno and Horkheimer on the culture industry. Therefore, in addition to clarifying certain aspects of the thinking of these theorists from Frankfurt, the authors propose a review of the profound nature of cinema as a cultural object.
\end{abstract}

\section{Keywords}

Culture, cultural industry, cultural management, film production, cinema (Source: UNESCO Thesaurus).

\section{Anotações sobre o fetiche cultural e 0 cinema}

\section{Resumo}

Sobre os fenômenos culturais, seja que se trate de produtos da indústria cultural ou de atividades de gestão cultural, recai uma série de imaginários. Posto isso, eles se comportam como fetiches ao modo da mercadoria. Este artigo se propõe revisar esse caráter de fetiche dos objetos culturais e particularmente do cinema, atendendo em detalhe alguns dos argumentos que Adorno e Horkheimer expõem sobre a indústria cultural. Desse modo, além de determinar alguns aspectos do pensamento dos teóricos de Frankfurt, propõe-se revisar a natureza profunda do cinema como objeto cultural.

\section{Palavras-chave}

cultura, indústria cultural, gestão cultural, produção cinematográfica, cinema (Fonte: Tesauro da Unesco). 
Se trata desde ahora de una especie de sociedad sin tierra, que sueña con su espiritualidad en vez de asirla a través de mil tareas de la vida cotidiana. Esto provoca el orgullo, como reacción de defensa, y un estrechamiento enfermizo de los vínculos sociales. He aquí una sociedad frenética en el aire.

\section{Jean-Paul Sartre}

En 1947 Max Horkheimer y Theodor Adorno publicaron su ya ilustre Dialéctica de la ilustración. El texto, como es bien sabido, encarna una crítica radical a la racionalidad política moderna. Probablemente uno de los términos técnicos de la publicación que más ha suscitado discusión es el de industria cultural. Desde el momento de su aparición hasta nuestros días han sido bastantes los teóricos que se han pronunciado al respecto, bien sea para suscribir la posición de estos pensadores como para refutarla. Sea la posición que se asuma, es claro que Adorno y Horkheimer abrieron un campo de discusión que aún se mantiene palpitante. Podríamos llegar a decir incluso que, de cierto modo, la discusión actual sobre las sociedades del espectáculo y las sociedades de control se alimenta silenciosamente de la discusión teórica abierta por ellos a finales de los cuarenta del siglo XX.

Sin embargo, a pesar del aporte que ha llegado a significar el concepto de industria cultural para los análisis críticos de la modernidad, no han sido pocos los autores que se han pronunciado en contra de la postura de Adorno y Horkheimer. Desde Walter Benjamin hasta Umberto Eco, pasando por Habermas y Noël Carroll, la evaluación del concepto no ha sido necesariamente complaciente (Carroll, 2002). Podríamos decir, siguiendo a Carroll, que el grueso de las críticas en contra se concentran en tres puntos fundamentales, a saber, el problema de la masificación, el de la pasividad del espectador y el de la obra como fórmula. En términos generales, el asunto de la masificación se puede formular del siguiente modo: en tanto la industria cultural produce mercancías, su destino es producir obras-cliché, esto es, producir obras en serie que no se diferencian entre ellas más que de una manera superficial, reproduciendo siempre el sentido común. Como segunda medida, el argumento de la pasividad del espectador sugiere que la obra de la industria cultural es necesariamente de fácil digestión, 
y para ello acude a formas estéticas simples, de fácil consumo, reduciendo así la experiencia estética del espectador-consumidor a su expresión más infantil. Finalmente, se sugiere que, a diferencia de la obra de arte genuina, la obra de la industria cultural reproduce irreflexivamente una serie de lineamientos formales que satisfacen las condiciones industriales de producción en serie y de entretenimiento del público-consumidor. De esta manera, la fórmula opera como recurso que garantiza el éxito de la obra como objeto de producción industrial.

Formulado de este modo, es fácil entender el mar de críticas que han recaído sobre el pensamiento de Adorno y Horkheimer. Por ello, es importante señalar que esta exposición de la industria cultural se satisface en las generalidades más que en la precisión de su formulación científica. Es decir, estas críticas recaen sobre una caracterización genérica y abstracta del fenómeno que, aunque asoma ocasionalmente en el texto original de los teóricos de Frankfurt, no agota la profundidad de su argumento. Una lectura rigurosa de la exposición que hacen Adorno y Horkheimer permite reparar en detalles que la exposición general pasa por alto y en los que se juega la filigrana argumentativa del problema. Este artículo se propone atender una pequeña serie de formulaciones precisas sobre la industria cultural con el ánimo de alcanzar alguna profundidad y precisión sobre ciertos aspectos del problema que usualmente son pasados por alto con el ánimo de ofrecer un semblante crítico sobre el cine considerado como fenómeno cultural. Para decirlo de un modo más preciso, este artículo se propone atender en detalle la caracterización de la obra cinematográfica como objeto cultural en tanto fetiche. Todo esto con el ánimo de hacer claridad sobre algunos aspectos políticos del cine que hasta el momento no han sido tematizados con suficiencia.

Vale la pena aclarar que, dada la naturaleza de nuestro objeto de estudio -el cine en cuanto fenómeno cultural-, la exposición del problema reclama una forma particular. El cine es desde su base material de procedencia heterogénea. Esto es, el cine es arte y a la vez industria, es expresión cultural y a la vez mercancía, es grito de independencia y a la vez mecanismo ideológico de seducción. En suma, el cine es una expresión de carác- 
ter impuro desde su base y por ese motivo las aproximaciones atentas a él deben proceder en consecuencia. La presente investigación es el resultado de una mezcla de heterogéneos. Este texto va de la teoría del cine a la del fetiche-mercancía, va del problema de la técnica de reproducción serial de imágenes a la teoría del Estado moderno. El cine es un fenómeno heterogéneo y asimismo lo debe ser el estudio que se aproxime a él. De ahí que el presente texto ofrezca más una serie de anotaciones que un organismo teórico cerrado.

\section{Modernidad, cultura e imagen técnica}

La 'cultura' como término que designa un problema diferenciado es un asunto fundamentalmente moderno. La palabra 'cultura' recoge una significación precisa sólo en la modernidad, encontrando en la formulación científica de las ciencias de la cultura, principalmente la antropología y la etnología, su expresión más acabada. Es necesario que hagamos un recorrido selectivo y veloz sobre la historia del concepto hasta el presente para poder reconocer sus presupuestos con el fin de establecer unas ciertas claridades sobre el cine en tanto objeto cultural.

El antecedente premoderno del término cultura proviene del lenguaje agrícola medieval. Para el siglo XIII, el latín colere designaba el estado de un cultivo, se usaba para aludir a un cultivo bien cuidado, conservado en buen estado. Ya para el siglo XVI, designaba más bien el acto mismo de cuidar del cultivo. Con ello, el término empezó a designar una acción por la cual un cierto objeto se desarrolla como producto del cuidado constante y consciente. Para 1718 la palabra cultura hizo su incursión en el diccionario de la lengua francesa para referirse a la facultad de cultivar espiritualmente algún tipo de habilidad o disciplina (artes, letras, ciencias) (Cuche, 2002, p. 11). Así, paulatinamente, la noción de cultura se alejó de su original ámbito agrícola para empezar a significar la instrucción de una mente cultivada. Surge con ello la imagen del hombre culto y la idea según la cual la cultura se opone a la naturaleza. Así, la cultura es lo privativamente humano, que funda un reino distinto al natural. Esta es una de las ideas más fuertemente arraigadas que la modernidad ha heredado del Siglo de las Luces. De ahí se sigue un fuerte universalismo de la idea de cultura como la acumula- 
ción de saberes y formas del hacer tradicionales que se transmiten entre los hombres de distintas generaciones. Universalismo enciclopédico que no es otra cosa que eurocentrismo encubierto: "El peso de la tradición ilustrada impuso conceptos tales como: 'la cultura es única y universal'; 'las artes, las ciencias y los libros son la forma más alta de cultura'; 'el tipo de cultura europea es avanzada y superior'; 'El progreso cultural existe y su parámetro es la civilización europea"' (Moreira, 2003, p. 15). En el contexto francés la idea de cultura fue relevada durante la segunda mitad del siglo XVIII por la de 'civilización', lo que arrastra consigo una concepción histórica y evolutiva de la realidad social de los seres humanos. Según Norbert Elías, el concepto de 'civilización' en su versión francesa unifica y universaliza lo que la categoría de 'cultura', apropiada por la tradición teórica alemana, diferencia y entiende como local:

El concepto de civilización atenúa hasta cierto punto las diferencias
nacionales de los pueblos y acentúa lo que es común a todos los seres
humanos (...). Por el contrario, el concepto alemán de cultura pone
especialmente de manifiesto las diferencias nacionales y las peculia-
ridades de los grupos (...) en el concepto de cultura se refleja la con-
ciencia de sí mima que tiene una nación que ha de preguntarse siem-
pre: “ ¿En qué consiste nuestra particularidad?” y que siempre hubo de
buscar de nuevo en todas partes su fronteras en sentido político y es-
piritual, con la necesidad de manifestarlas además (Elías, 2008, p. 85).

De ahí que la acepción alemana de cultura fuera la que resultara más determinante dentro del contexto de la vida de los Estados-nación modernos.

En este punto vale la pena recordar el papel definitivo que jugaron las expresiones artísticas, fundamentalmente las pictóricas, durante el siglo XIX, con el fin de fortalecer la idea local de cultura nacional por medio de la construcción de símbolos que cristalizaran y mistificaran el imaginario en torno a las culturas nacionales. El Estado moderno debió esforzarse por unificar ese nuevo sujeto histórico del siglo XIX denominado masa y para ello debió recurrir, entre otros, a una serie de recursos simbólicos de unificación y lealtad. De ahí que el arte oficial y académico cumpla la función simbólica fundamental de mistificar una mitología nacional alimentada de imágenes del pasado plenas de evocación de la fuente prístina de un origen primordial. Siguiendo a historiadores de la talla de Hobsbawm o Gell- 
ner, Anthony Smith lo formula de esta manera: "The many new themes of artists, writers and composers, who expanded and enriched the language of poetry, drama, music, and sculpture, can be read as so many 'invented traditions', forged to meet new needs through iterative symbolic practices which claim a putative link with the communal past” (Smith, 2010, p. 47). El arte del siglo XIX cumple la función de establecer las bases simbólicas que fundamentan la imaginería de un pasado común y originario que soporta la identidad cultural de una nación. Imaginarse como nación pasa necesariamente por construirse un pasado mítico identitario que unifica las masas en función de su porvenir. Ahora bien, con la aparición de las artes técnicas, con la fotografía y el cine a la cabeza, este propósito estatal de construcción simbólica del terruño encontrará sus herramientas idóneas.

Retomando nuestra breve genealogía del término cultura, es importante concentrarse en el momento y el juego de condiciones por las cuales la palabra devino concepto científico en la base de las nacientes antropología y etnografía del siglo XIX. Con las florecientes ciencias sociales y humanas en el siglo XIX, la categoría 'cultura' alcanzó un nuevo estatuto. Bebiendo de la doble fuente del positivismo newtoniano y del dualismo cartesiano que distingue el reino natural del humano (Wallerstein, 2007, p. 4), las ciencias de la cultura encontraron su espacio dentro del cuadro de los saberes científicos modernos. Se trataría así de hallar las leyes regulares y mensurables que gobiernan la vida autónoma de los hombres como sociedad o cultura. Se atribuye a Edward Burnett Tylor la invención del sentido científico del término. Para 1883 él mismo introdujo la cátedra de antropología en Oxford, en medio de la discusión que ocasionó un saber que aspira a ser científico y cuyo objeto, la cultura, escapa a la regularidad del comportamiento de la naturaleza. Justamente por esta inestabilidad epistemológica en la que se encuentran las ciencias de la cultura, ellas tienden a una inagotable tarea de relativización de sus propios axiomas. En el contexto de las florecientes sociedades de masas era urgente un saber sobre este nuevo sujeto histórico, pero a la vez era imperativo relativizar este conocimiento para hacerlo sensible a su objeto. ${ }^{3}$ De este modo, la noción de cultura en su

3 Emanuel Wallerstein logra exponer con claridad la magnitud política de esta dificultad epistemológica: "Políticamente el concepto de leyes deterministas parecía ser mucho más útil para los intentos de control tecnocrático de los 
acepción científica tendería lentamente a dejar atrás los universalismos de sus formulaciones iniciales al precio de poner en riesgo su estatuto científico. Así, se abre un camino inagotable de reflexividad epistemológica en el seno de las ciencias sociales y humanas que hace que hasta sus categorías fundamentales, la cultura en este caso, se hagan volátiles.

Es justamente allí, en el ojo del huracán, donde los recursos técnicos de la fotografía y del cine encontrarán un lugar privilegiado. Ante la improbabilidad de la ciencia, la técnica viene a redimir al conocimiento de su crisis. Para decirlo en el lenguaje un poco críptico de Vilém Flusser: "Precisamente en esta etapa crítica, en el siglo XIX, se inventaron las imágenes técnicas a fin de hacer los textos nuevamente imaginables, para colmarlos de magia y, así, superar la crisis de la historia” (Flusser, 1990, p. 15). Las ciencias de la cultura corren con el doble riesgo del positivismo extremo que defrauda a su huidizo objeto o, por el contrario, de la pura especulación que no logra el nivel de rigor y exactitud reclamados a la ciencia en la modernidad. En este escenario llega la fotografía como antídoto al dilema. Ella ofrece el objeto como imagen, salvando su apariencia no mensurable, su singularidad mágica no positiva. Pero a la vez documenta con una supuesta -pero obviamente falsa- neutralidad técnica su realidad sensible. Entre la técnica y la magia, la imagen fotográfica viene a redimir a las ciencias de la cultura de su inestabilidad epistemológica, pues las aproxima a la singularidad de su objeto que no se comporta según leyes universales, pero a la vez ofrece, al menos como promesa, la documentación técnica de la realidad en beneficio de su conocimiento positivo. Juan Naranjo lo ilustra de la siguiente manera: "La fotografía desempeñó un papel fundamental en esta transformación cultural, en que la imagen fue ganando terreno a la palabra impresa, ya que éste es uno de los medios en que más se desdibujan las fronteras entre la realidad y su representación" (Naranjo, 2006, p. 11). El hipotético realismo fotográfico permite que se dé un equívoco conveniente para la antropología, según el cual estamos frente a la singularidad misma del ob-

movimientos potencialmente anarquistas por el cambio, y políticamente la defensa de lo particular, de lo no determinado y lo imaginativo parecía ser más útil, no sólo para los que se resistían al cambio tecnocrático en nombre de la conservación de las instituciones y las tradiciones existentes, sino también para quienes luchaban por posibilidades más espontáneas y más radicales de introducir la acción humana en la esfera sociopolítica” (Wallerstein, 2007, p. 13). 
jeto cultural estudiado, a la vez que, convertido en imagen, contamos con él como material cuantificable, archivable, manipulable y demás. Con la fotografía estamos entre la generalidad de la teoría que se ve ilustrada en cada imagen y la singularidad de cada rostro que como un tipo viviente se hace irreductible al cálculo de sus rasgos. De ahí que la fotografía científica de este tipo adoptara unos protocolos muy precisos para estandarizar a su objeto en la misma medida que lo conservaba como singularidad irrepetible en la imagen. Este tipo de fotografía se alimentaría de la antropometría para regular sus variaciones. No es casual que los usos fotográficos carcelarios y clínicos de la época adoptaran el mismo comportamiento, pues en su ejercicio de control buscaban estandarizar la información del criminal o del paciente, conservando la singularidad de su aspecto como caso asociable a un individuo. "Al combinar la fotografía con la antropometría pudieron obtenerse medidas estandarizadas sobre el cuerpo humano, lo que permitió la comparación y al mismo tiempo, reunir de forma económica una gran cantidad de información" (Naranjo, 2006, p. 16). Entre la técnica y la magia es lo mismo que entre el aura y el control.

El caso cinematográfico es aún más claro. Las potencias narrativas del medio permiten que la antropología construya sus relatos de un modo análogo al modo en que la ficción construye los propios, pero no con el fin de defraudar la realidad, sino, por el contrario, de construirla como objeto de conocimiento científico por medio de la imagen. De tal modo que el espacio narrativo y el científico se reforzaban en una estrategia aparentemente paradójica. Marc Henri Piault dice lo siguiente de este exótico maridaje:

A través de estas operaciones se elaboró uno de los constituyentes esenciales de todo relato, ya sea cinematográfico o narración de la experiencia etnológica: el personaje filmado o la persona en su autoctonía antropológica fueron construidos, por una parte, a lo largo de un proceso atributivo y cualificativo de identificación con respecto a otras figuras de comprensión (Piault, 2002, p. 20).

Entre la ciencia y la narrativa, a través del uso del medio cinematográfico, la antropología concilia sus opuestos y satisface sus necesidades como 
saber de la cultura. De este modo, tanto el cine como la fotografía, por su doble naturaleza de imagen y de técnica, salvan a las ciencias de la cultura de su ambigüedad epistemológica. Ahora bien, la pregunta que nos ocupará más adelante consiste en lo siguiente: ¿qué hace el arte cinematográfico y ya no la antropología con este equívoco (técnica/magia) para el caso de sus obras consideradas de carácter cultural? Ya llegaremos a ello con un poco de paciencia.

Para finalizar nuestra breve y fragmentaria genealogía del concepto de cultura, vale la pena que nos detengamos en uno de los usos contemporáneos más frecuentes del concepto con el fin de aclarar un conjunto de prácticas características de los gobiernos nacionales actuales. Me refiero a la idea por la cual la cultura ya no es sólo un objeto de conocimiento, sino además un campo de gestión. La idea más palpitante en relación con la cultura en el presente la ha hecho objeto de la denominada gestión cultural, claramente heredera del comportamiento de la industria cultural. Aunque la gestión cultural surge como resultado de la actitud de defensa del patrimonio cultural de las naciones frente al manoseo de la industria cultural, no sería del todo descabellado considerar la gestión cultural como industria cultural de Estado.

Es claro que desde la edad media se puede reconocer un esfuerzo por parte de los gobiernos por establecer un conjunto de referentes simbólicos para su población. El uso de banderas, escudos, códigos simbólicos en las armas y armaduras viene desde bien atrás. Tampoco es difícil rastrear el modo en que los nacientes Estados-nación del siglo XIX se esforzaron por construir, como dijimos arriba, relatos épicos sobre sus orígenes con el fin de establecer una versión oficial de sí mismos para garantizar el sentido de pertenencia y de lealtad de sus masas. Incluso, no sería difícil ver en el programa propagandístico de Lenin, Mussolini o Goebbels el esfuerzo por unificar a las masas en torno a un proyecto cultural. No obstante, el sentido preciso de gestión cultural es más reciente. Sólo hasta la década de los sesenta del siglo pasado se puede hablar en sentido institucional y operativo de gestión cultural. "A partir de 1960 y 1980, la gestión cultural se ha ido incorporando al planteamiento de las políticas públicas de los estados” 
(Moreira, 2003, p. 10). Al hablar de gestión cultural hablamos de gestión administrativa de Estado, lo cual significa la aparición de organizaciones e instituciones administrativas y presupuestalmente autónomas, dedicadas a la gestión de la vida cultural de una nación. El Estado en su centralidad asume como su responsabilidad la constitución y organización de unidades operativas de gestión de la cultura en nombre de la prosperidad:

\begin{abstract}
De esta manera el agente Estado interviene en nuestro contexto social de forma enérgica y contundente con procesos de legitimación de demandas y necesidades de la población y la institucionalización de organizaciones culturales (...). Este proceso se realiza gracias a la aprobación de políticas públicas aportando unos recursos y generando una necesidad de profesionales que desarrollen estos programas (Sempere, 2002, p. 222).
\end{abstract}

En esta medida, la gestión pública opera como una red institucional y de profesionalización disciplinar que responde a una serie de necesidades de unificación y administración de la vida social de las masas.

Resulta paradigmático el caso francés. Para 1960, bajo el gobierno de Charles de Gaulle, Malraux sería nombrado como el primer ministro de cultura de la historia. El naciente ministerio se ocuparía de lo cultural en un sentido diferente a la gestión educativa que venía cumpliendo su gobierno. Este ministerio tendría tareas específicas y un espacio de acción perfectamente delimitado según procedimientos administrativos específicos. "Malraux organizó su ministerio centrándose en lo cultural y desprendiéndose de las responsabilidades de la educación nacional que había sido un área estratégica del gobierno francés desde la revolución. El suyo sería un ministerio de los artistas, de los creadores, de la creación" (Castiñera de Dios, 2013, p. 82). El nuevo proyecto ministerial ocupaba un lugar estratégico en el panorama político de la época, pues a través suyo se buscaba consolidar la unidad de un pueblo que aún no se reponía de la ocupación nazi. Se trataba de un proyecto laico de unificación nacional:

La preocupación de Malraux se centraba específicamente en la cultura como factor de unión de una sociedad fragmentada. Al crear la red de casas de cultura describió a éstas como nuevas catedrales laicas que tienen que volver a ser los espacios que congreguen a 
Ios franceses en torno a un culto -no ya el de la religión sino el del arte- para volver a reestablecer un tejido social que había dañado la historia reciente (Castiñera de Dios, 2013, p. 84).

De esta forma se consolidó una entidad específica del gobierno como gestora y promotora de cultura. Claro, no sin reclamos por partes de los anarquistas y los movimientos antiestatales del 68. Algunas de sus preguntas, legítimas, serían las siguientes: ¿ por qué el arte, con todo su poder de subversión y a la vez de propaganda, sería un objeto natural de preocupación por parte de un Estado democrático? ¿Por qué es tarea natural del Estado llevar al obrero al museo?

Veinte años más tarde, ya bien entrada la década de los ochenta, el término gestión cultural sería acunado dentro de la terminología técnica internacional y se expandiría rápidamente por todas las latitudes. "Según un informe de la Organización de Estados Iberoamericanos (OEI), la noción de gestión cultural ingresa al discurso cultural en Iberoamericana hacia la segunda mitad de la década de 1980, tanto en las instituciones gubernamentales como en los grupos culturales comunitarios" (Moreira, 2003, p. 23). Y acompañando a esta oficialización de la gestión cultural se le añade su maridaje con la noción de desarrollo. Para la década de los ochenta la gestión cultural se convirtió en agente de desarrollo de las naciones y por tanto en elemento fundamental de la agenda administrativa de los gobiernos nacionales. La Unesco lideró la formulación estratégica de este maridaje cultura/desarrollo. La idea de desarrollo de las naciones al margen de la conservación y promoción de la cultura se ha hecho, desde hace dos décadas, insostenible. El modelo estrictamente económico del desarrollo ha cedido a uno más integral, según dicen los especialistas. Recientemente la idea de desarrollo se emparenta con la de responsabilidad cultural. De la idea de lo cultural como freno para el desarrollo se pasó a la de cultura como factor positivo para su despliegue (Maccari y Montiel, 2013, p. 49). En consecuencia, la tarea de la gestión cultural llega a desbordar el estrecho espacio de las artes para ampliarse al de las formas de expresión social idiosincráticas en general. La gestión cultural se amplía más allá de las formas culturales de élite. Es decir, se democratiza. Ya no sólo el arte culto es objeto de 
administración por parte de las instituciones, sino el conjunto en general de formas expresivas de una sociedad en beneficio del proyecto de unificación y prosperidad de las naciones. De ahí la suspicacia de Jean Dubuffet ante la inevitable fundación del ministerio liderado por Malraux: "La única imagen que yo tengo del estado es la de la policía, sólo puedo imaginar un ministerio de cultura como un departamento de policía con sus comisarías, sus inspectores, sus agentes ..." (Castiñera de Dios, 2013, pp. 80-81).

Como sea, podemos ver en qué medida la gestión cultural, en manos del Estado, parece ubicarse en la misma posición ambivalente de las ciencias de la cultura. Por un lado, desempeña una función de formación estética y espiritual en beneficio del cultivo de las almas, pero por otro lado realiza la labor pedagógica de aquel que instruye sobre la patria a la que pertenece su pueblo. La gestión cultural se ubica entre el conocimiento y la experiencia estética. Adicionalmente, en sus formulaciones más recientes, es expedito de qué manera este doble carácter de la cultura facilita la gestión administrativa de lo cultural. La cultura ya no sólo es objeto pasivo de un conocimiento, sino material para una acción preformativa sobre los flujos sociales. En este punto es necesario acudir a Adorno y Horkheimer. Diremos de manera anticipada que esta actividad preformativa sobre las masas depende en gran medida del carácter de fetiche que alcanza la obra de carácter cultural. Nos concentraremos luego en el caso cinematográfico.

Resumamos para continuar: un breve y selectivo recorrido histórico nos ha permitido entender los sentidos estratégicos que ha tenido el término cultura hasta su formulación más actual en cuanto objeto de administración en la gestión cultural. De este modo, se ha hecho visible en qué medida el término posee un doble carácter, a saber, es objeto singular de experiencia y a la vez objeto de un conocimiento genérico. El objeto cultural se encuentra a medio camino entre la estética y la epistemología. De ahí que el museo antropológico, por dar un ejemplo claro, satisfaga a través de la imagen fotográfica la necesidad de conocimiento y a la vez la urgencia de experiencias sensoriales novedosas. ${ }^{4}$ De este modo, las artes técnicas de

4 A propósito de esto, el texto de Elizabeth Edwards resulta esclarecedor. Ella señala lo siguiente: "La ambigüedad que caracteriza a la fotografía se corresponde con la identidad incierta, no sólo de la antropología, sino también de 
la imagen (cine y fotografía) satisfacen a plenitud el doble requerimiento que hace este objeto inestable, la cultura. Al respecto, algunos aportes precisos de Adorno y Horkheimer nos pueden dar luces.

\section{Industria cultural y fetiche}

Cuando los autores de la Dialéctica de la Ilustración someten a crítica a la industria cultural, no meramente están haciendo una crítica puntual de un sector productivo en particular. Por el contrario, la crítica a la industria cultural entraña una crítica a la forma misma de la modernidad en su expresión más elaborada. Así, para ellos, la industria cultural no es un fenómeno parcial de la modernidad, sino la expresión de su consumación. La crítica de la industria cultural no es sólo la crítica de un sector de la producción tardomoderna, sino del modelo mismo del sistema. Ella encarna los principios de la producción en las sociedades en las que la generación de excedentes ya está garantizada y en la que entonces es necesaria la producción de consumo. ${ }^{5}$ En esta medida, la crítica de la industria cultural es una crítica generalizada a la modernidad tardía. Por ello, los autores no sólo someten a examen el término industria, sino, necesariamente también, el término cultura.

Al respecto, Adorno y Horkheimer aseguran lo siguiente: "Hablar de cultura ha sido siempre algo contra la cultura. El denominador común 'cultura' contiene ya virtualmente la toma de posesión, el encasillamiento, la clasificación que entrega la cultura al reino de la administración” (1988, p. 7). El grueso de la teoría encuentra en el concepto de cultura el triunfo de una sociedad autoconsciente de su historicidad. En esta autorreflexión el denominativo cultura operaría como una categoría de reconocimiento de lo que somos en cuanto sociedad histórica. Sin embargo, los teóricos de Frankfurt, lejos de ver la emergencia del triunfo de una racionalidad autoconsciente, ven la consolidación de una gran máquina de administración de la vida social de los hombres. Para ellos esta forma de la autoconciencia es sinónimo de

la práctica museística” (Naranjo, p. 253). Tanto el museo como las ciencias humanas y la fotografía flotan en este escenario de incertidumbre que problematiza la escisión moderna entre ciencia, especulación y artes, entre conocimiento, retórica y experiencia estética.

5 En relación con esto, autores contemporáneos como Paolo Virno, Maurizio Lazzarato, Toni Negri y Michael Hardt han teorizado ofreciendo resultados bastante notables. 
control. La noción de cultura distribuye las diferencias en un plano taxonómico que las hace susceptibles de clasificación, ordenamiento y administración. La vida misma del concepto cultura supone el comportamiento de lo que él designa como objeto de cálculo y gestión. Una vez designado como cultura, tal objeto se somete a la intromisión de aquel que calcula y administra. Es decir, la denominación de un fenómeno como cultural presupone su devenir 'objeto', esto es, sustancia pasiva que se ofrece para ser conocida y posteriormente intervenida según un cálculo y una proyección. Por eso, prosiguen los autores: "Sólo la subsunción industrializada, radical y consecuente, está en pleno acuerdo con este concepto de cultura” (Horkheimer y Adorno, 1988, p. 7). Expuesto como cultural, todo fenómeno es develado como 'objeto' dispuesto para el conocimiento apropiador y, asimismo, como mercancía. El objeto de conocimiento es tan pasivo como la mercancía. En cuanto objeto cultural todo está disponible para ser observado y en consecuencia para ser exhibido al modo de la mercancía turística. Incluso sin ser intercambiado por dinero, el objeto cultural supone su circulación, su aceleración para el conocimiento y la experiencia. El modelo de la libertad y perpetuación cultural de las naciones es el de la mercancía, esto es, el de la acelerada circulación en su exhibición. ¿De qué sirve la cultura si no se la exhibe? ¿Qué mejor medio para el despliegue de este constitutivo valor exhibitivo del objeto cultural que la fotografía y el cine, los grandes aceleradores de la circulación por la imagen? En el entusiasmo del antropólogo y del turista, armados con sus cámaras, resuena el entusiasmo del consumidor frente a la vitrina.

Así, el concepto de cultura supone designar un fenómeno social como 'objeto' natural para el conocimiento y la experiencia. En esta medida, el concepto de cultura, como el fetiche de la mercancía, oculta por principio su procedencia, esto es, su modernidad. El concepto de cultura no sólo objetualiza aquello a lo que se refiere, sino que se fetichiza a sí mismo al naturalizarse en cuanto, por principio, oculta sus compromisos con la cosificación del mundo, característica de la modernidad. En su texto breve titulado Crítica de la cultura y sociedad, Adorno lo formula así: "La cultura sólo se puede idolatrar si ha sido neutralizada y cosificada" (Adorno, 2008, p. 14). Sólo como objeto la cultura es un asunto, y en tanto que tal, motivo de conocimiento, especulación, circulación y exhibición. Sin embargo, la 
cultura como concepto se oculta al suponer que se refiere a objetos naturales. La cultura como concepto se supone inmanente a las culturas a las que se refiere. El colmo del fetiche cultural es suponerse inmanente al mundo, natural a él, esto es, exterior a todo cálculo o gestión. La industria cultural explotará este componente fetichista.

En su Resumen sobre la industria cultural, Adorno insiste en la necesidad de diferenciar entre la industria cultural y la cultura de masas. Él asegura que llamar a la industria cultural por otro nombre, cultura de masas, se presta para un equívoco no meramente nominal, sino sustancial. En sus palabras es formulado de este modo:

En nuestros borradores hablábamos de "cultura de masas". Pero sustituimos esta expresión por "industria cultural" para evitar la interpretación que agrada a los abogados de la causa: que se trata de una cultura que asciende espontáneamente de las masas, de la figura actual del arte popular. La industria cultural es completamente diferente (...). En todos sus sectores fabrica de una manera más o menos planificada unos productos que están pensados para ser consumidos por las masas y que en buena medida determinan este consumo (Adorno, 2008b, p. 295).

La industria cultural afirma en su defensa que sus productos responden a las solicitudes espontáneas de las masas y en esa medida sus contenidos brotan de manera inmediata, no mediada, de la creatividad natural de las personas. En esta medida, sus obras serían franca expresión de la vida social. Sin embargo su naturaleza industrial sugiere otra cosa. En cuanto industria, ella se comporta según un cálculo de costos y beneficios especulando siempre con su eficacia. Los productos de la industria cultural no son, para Adorno, obras de arte devenidas mercancías. Más bien, son mercancías sin más: "Las obras espirituales del estilo de la industria cultural ya no son también mercancías, sino que son mercancías y nada más" (Adorno, 2088b, p. 296). En tanto que mercancías son fetiches.

Desde el análisis de Marx es claro de qué forma la mercancía, expuesta en la vitrina, circulando en el mercado, oculta por naturaleza las condiciones sociales de su producción, esto es, la explotación que la hizo posible. Su belleza y acabamiento invisibiliza el trabajo que la trajo al mun- 
do. Sin embargo, con los productos de la industria cultural en tanto mercancías hay un componente adicional. Sobre ellos recae el imaginario de la autoría. La idea de un autor detrás del producto de la industria cultural lo reviste de un aura que lleva al colmo su poder hipnótico, su carácter de fetiche. Mientras cualquier mercancía aparece como el resultado impersonal del trabajo en la fábrica, el producto de la industria cultural se ofrece como el resultado de la inventiva individual de un autor. "Cada producto se presenta como individual; la individualidad sirve para reforzar la ideología, pues con ella se produce la impresión de que lo completamente cosificado y mediado es un refugio de la inmediatez y de la vida" (Adorno, 2008b, p. 297). La figura de una individualidad que firma el producto encierra el truco perfecto. La firma individual oculta el trabajo colectivo, oculta la planificación, la distribución y especialización del trabajo. En suma, la firma autoral que supuestamente está detrás de la obra de carácter cultural oculta la planeación natural de tal obra en cuanto mercancía. El producto de la industria cultural es revestido del aura de la autoría y con ello invisibiliza su carácter de mercancía. Así, la industria cultural se fortalece del equívoco que ella misma produce. Equívoco por el cual sus formas racionalizadas pasan por espontáneas. "El resultado es la mezcla, esencial para la fisionomía de la industria cultural, entre streamlining, dureza y precisión fotográfica (por una parte) y residuos individualistas, entusiasmo y romanticismo racionalizado (por otra parte)" (Adorno, 2008b, p. 298). De este modo, sobre un objeto producido según procedimientos industriales recae el aura de la producción artesanal, de la producción no industrial. Adorno prosigue su descripción de este modo: "Si aceptamos la definición de la obra de arte tradicional mediante el aura, mediante la presencia de algo no presente (Benjamin), lo que define a la industria cultural es que no contrapone estrictamente al principio aurático algo diferente, sino que conserva el aura en descomposición como una niebla" (2008b, p. 298). De nuevo, la obra cultural oscila entre el aura y la mercancía, entre lo irrepetible y la reproductibilidad técnica. Lo cultural goza de este doble carácter y se nutre de él. Sea como objeto de conocimiento en las ciencias de la cultura, como objeto de administración en la gestión cultural o como objeto de producción industrial, el objeto cultural se fortalece bebiendo de esta doble fuente. Se trata de una incoherencia productiva. 
Ahora bien, podríamos trasladar perfectamente lo que señala Adorno sobre la figura del autor a la idealización de la obra como producto cultural. Podríamos decir que cierto tipo de obras que se ofrecen como expresión cultural de un pueblo, de una idiosincrasia, reciben el mismo trato que recibe una supuesta obra autoral. En ambos casos sobre el producto recae la idea de una espontaneidad creativa que la hizo posible. Sobre el producto de carácter cultural recae la idea fetichista de la espontaneidad de su procedencia. Incluso, se suele considerar que las expresiones culturales ofrecen una resistencia al frío mundo de la circulación en el mercado. Se le pide al artista indígena que redima a su tribu a través de su obra, se le solicita al artista gay que manifieste con sinceridad la idiosincrasia de la minoría a la que pertenece, se quiere ver en la obra del artista negro una oda contra el racismo. Con la activación de este halo que recubre la obra cultural se confunde el contenido edificante con la experimentación artística. Nicolás Bourriaud lo expone de este modo: "Los tiempos posmodernos ven nuevamente obras que manifiestan sentimientos edificantes disfrazados de una 'dimensión crítica', imágenes que se redimen su indigencia formal por la exhibición de un estatuto minoritario o militante, o discursos estéticos que exaltan la diferencia y lo 'multicultural' sin saber claramente por qué" (Bourriaud, 2009, p. 25). De este modo, el producto cultural, materializado según un proceso industrial planificado, pasa por espontaneidad revolucionaria y con ello los supuestos medios de preservación de la diferencia no son otra cosa que meros objetos de producción industrial. De nuevo Bourriaud nos da luces al respecto:

La supuesta diversidad cultural preservada bajo la campana de vidrio del "patrimonio de la humanidad" termina siendo el reflejo invertido de la estandarización general de los imaginarios y de las formas: cuantos más vocabularios plásticos heterogéneos de tradiciones visuales múltiples no-occidentales integran el arte contemporáneo, más claramente aparecen los rasgos distintivos de una cultura única y globalizada (Bourriaud, 2009, pp. 11-12).

Gran eficacia la del aura que recubre al objeto cultural. Según Bourriaud, la actitud compasiva de aquel que trata de salvaguardar la diferencia cultural y minoritaria no hace más que ponerla en bandeja de plata para 
su apropiación como objeto de consumo en una suerte de gran acumulado en el que las culturas se suman unas a otras a través de sus objetos. Resulta contradictorio que en el mismo contexto en que la erradicación inmisericorde del pasado está en la base de los procesos de modernización de la vida social, el proyecto de la industria y la gestión cultural nos encomie a preservar en la imagen las formas minoritarias o en vías de extinción. De este modo, la obra de carácter cultural se ha convertido en el espacio de expiación de la culpa y en consecuencia en mecanismo de perpetuación de aquello que la produce. ${ }^{6}$

A propósito de este tema, Hal Foster redactó un texto indispensable, "El artista como etnógrafo". En él, Foster señala una nueva tendencia del arte desde la última década del siglo XX. Se trata del paradigma del artista como etnógrafo. Se trata de un desplazamiento en el arte: "es el otro cultural y/o étnico en cuyo nombre el artista comprometido lucha las más de las veces" (Foster, 2002, p. 177). Y, como lo señala el autor, el gran peligro al que se expone este tipo de arte es el de la idealización del otro. Esta idealización tiende a hacer del otro el lugar natural de la verdad. Como si su ser otro le otorgara una relación más íntima con la verdad de lo que somos. Lo otro desafía al hombre occidental como su verdad perdida. Se trataría así de una actualización estética del mito del buen salvaje. En consecuencia la tarea del arte sería la de darnos noticia de esta verdad a través de su obra cultural con miras a alterar nuestra propia identidad. De este modo, el imperativo para el artista sería el siguiente: ¡compórtate como un antropólogo! ¡Regrésanos nuestra verdad perdida a través de la obra antropológica! "Una nueva envidia del etnógrafo consume a muchos artistas y críticos

6 Al respecto la posición de Jacques Rancière es definitiva. Para él, la solicitud de intervención del arte por parte del Estado y la industria no es más que otro recurso por el cual se reafirman las políticas consensuales imperantes. El consenso supone un acuerdo previo sobre las condiciones mismas de lo político, acuerdo por el cual se ha distribuido y jerarquizado quién tiene voz activa y quién no. Así, la función del arte no sería otra que la de incluir a aquel que no tiene voz ni participación política dentro del conjunto estadístico de quienes han sido tenidos en cuenta por el Estado sin que esto signifique su participación efectiva en la política como producción real de disenso. El excluido suele ser incluido a través del arte, pero sólo en sentido nominal y estadístico, nunca en sentido real. "El excluido hoy día reduce esta dualidad a la simple figura social de aquel que está fuera y al que el arte debe contribuir a meter dentro. Esta figura del excluido pertenece evidentemente a la reconfiguración consensual de los elementos y de los problemas de la comunidad. Por un lado, el excluido es el producto de la operación consensual. El consenso busca una comunidad saturada, limpia de sujetos sobrantes del conflicto político" (Rancière, 2005, p. 60). La lógica del consenso produce la categoría del excluido y la racionaliza según sus necesidades estadísticas y jerárquicas para luego incluirla a través de remiendos sociales por el arte y la gestión cultural. 
(... ) estos artistas y críticos aspiran al trabajo de campo en el que la teoría y la práctica parecen reconciliarse” (Foster, 2002, p. 186). Teoría y práctica, arte y conocimiento, belleza y verdad. Insistimos en este punto para añadirle algo: el doble carácter de la obra cultural, a saber, su carácter estético y a la vez epistemológico, encierra la base de su fetichización. La obra cultural encierra la opción de una experiencia y de un conocimiento que esconde una verdad que se supone brota espontáneamente de la vida, sin cálculo alguno. La obra cultural, producida en el seno de la administración de la industria y de la gestión estatal, se ofrece como el lugar de un conocimiento y una experiencia de lo verdadero en su naturalidad. El fetiche cultural brilla con la luz de la verdad.

Tras haber reconocido la procedencia y el carácter del fetiche de la mercancía cultural, podemos concentrarnos brevemente en el caso cinematográfico.

\section{Algunos aportes sobre el cine y la cultura}

Líneas arriba señalábamos de qué modo la obra de carácter cultural/antropológico ocupa un lugar particular en cuanto medio de reivindicación de las minorías en ella representadas. Este tipo de obra, se dice, le otorgaría naturalmente vocería a las expresiones idiosincráticas que no la poseen. En el campo cinematográfico, a este tipo de obra se le denomina, por lo general, como cinematografía nacionaly de autor por oposición a la industria de Hollywood. En el espacio cinematográfico esta tensión entre la obra cultural y la industrial insiste por contrariedad en el carácter marginal, exterior a la industria, de la primera. Podríamos caracterizar el asunto del siguiente modo: "Especially in the West, national cinema production is usually defined against Hollywood. This extends to such a point that in western discussions, Hollywood is hardly ever spoken of as a national cinema, perhaps indicating its transnational reach" (Croft, 2002, p. 26). La estructura de producción, distribución y exhibición del modelo de Hollywood establece unas claras condiciones de producción industrial, de tal suerte que la obra extranjera o autoral que escapa a tales condiciones recibe, por negación, el mote de 'cinematografía nacional'. Mientras el cine de Hollywood existe como objeto de exportación por su base industrial transnacional, las 
cinematografías nacionales se ofrecen al espectador como aquellas obras que escapan a este modelo. Así, la definición de cinematografía cultural, autoral o nacional, es relativa al modelo del que pretende escapar: Hollywood. Sin embargo, el concepto de cinematografía nacional es bastante borroso. En su artículo "Reconceptulizing National Cinema/s", Stephen Croft hace visibles los significados variables y hasta contradictorios del término. Croft distingue siete sentidos usualmente atribuidos a la expresión 'cine nacional': estas variaciones del término van desde la cinematografía del tercer mundo hasta la cinematografía angloparlante, pero no americana, que busca en su región reproducir el modelo de producción industrial hollywoodense (Croft, 2002, p. 27). Así, en esta categorización podrían entrar cinematografías tan distintas como la de Dogma 95, el denominado tercer cine latinoamericano o la cinematografía mainstream de la India-Bollywood-. Como sea, esta dicotomía entre el cine nacional y el cine industrial de Hollywood se presta para cometer una serie de errores fetichizantes.

Por lo general, se suele asociar las cinematografías alternativas a mecanismos de financiación no privados, en lo que Thomas Elsaesser denomina "un modo de producción cultural" (Elsaesser, 1989, p. 3). Para él, se trata de un modo de producción alternativo al industrial. Para el modo de producción cultural, la financiación depende de becas de creación, concursos, premios y facilidades provenientes de la legislación estatal. Pero esta oposición suele ocultar algo; dada esta caracterización antagónica se dice que el cine cultural depende en gran medida de la acción estatal mientras la producción cinematográfica de Hollywood existe justamente por su independencia de la intervención del gobierno americano. Esto es falso no sólo porque el cine marginal en muchísimas ocasiones depende de dineros de la industria privada, sino además, y sobre todo, porque la cinematografía de Hollywood es dependiente, si bien no en estricto sentido financiero, sí en sentido administrativo, de las políticas del Estado. Hollywood no habría surgido ni mucho menos se habría mantenido sin la intervención favorable del Estado norteamericano. Ahondemos en ello: como muy bien logra exponerlo Rubén Arcos Martín en su texto dedicado al cine como fenómeno cultural, aunque se suele tener la idea de que Hollywood logró su imperio al margen de la intervención estatal, un análisis cuidadoso del fe- 
nómeno arroja resultados distintos: "el sector cinematográfico constituye uno de los casos más notables en lo referido a la cooperación entre la empresa privada y el gobierno norteamericano" (2010, p. 42). Aunque es escasa la bibliografía al respecto, es posible afirmar que el apoyo del Estado americano fue indispensable en el fortalecimiento de la industria cinematográfica americana al interior de su país como estrategia para proyectarse como industria transnacional. Más delante Arcos Martín señala:

\begin{abstract}
hemos de señalar que la ausencia de un ministerio de cultura, de cuotas de exhibición o de subvenciones no implica la inexistencia de apoyo por parte del gobierno federal, de políticas en otros ámbitos y de legislación que, en definitiva, constituyen factores decisivos que posibilitan la creación y permanencia en el tiempo de ese escenario de dominio de la industria cinematográfica norteamericana (Arcos Martín, 2010, p. 61).
\end{abstract}

¿Por qué inferir de la ausencia de apoyos económicos a través de premios o estímulos la ausencia total de apoyo y estrategia gubernamental? El estado americano entendió que el cine era un vehículo idóneo de promoción de sus productos con miras a la expansión global de sus mercados, no sólo cinematográficos sino de manufacturas. Se sabía bien que introduciendo sus películas a lo largo del mundo, Hollywood introduciría automóviles, lavadoras y demás productos de la industria americana en los hogares del mundo. Por ello, el estado fortaleció un plan jurídico ambiguo en términos de la ley antimonopolio. Para 1918 el congreso eximiría a ciertos sectores de la ley antimonopolio con miras a fortalecer su eficacia económica en el extranjero. Entre estos sectores, uno de los más aventajados era el cinematográfico (Arcos Martín, 2010, p. 67). Este aparato jurídico facilitaría de consolidación del emporio industrial de Hollywood al precio de hacer la vista gorda ante los principios de protección antimonopolio fundamentales para el gobierno americano: "Por una parte se reconocía que estas asociaciones representaban un peligro para la libre competencia y los intereses de los consumidores norteamericanos, pero a la vez se incentivaba su formación para fortalecer la competitividad de Estados Unidos en el mercado mundial" (Arcos Martín, 2010, p. 67). Adicionalmente, el gobierno americano ofrecía sus servicios diplomáticos para hacer frente a cualquier dificultad comercial con los gobiernos extranjeros en términos de bloqueos o 
desestímulos a la proyección filmica. Heredando de esta actitud, podemos ver cómo en el presente las mesas de negociación de los tratados comerciales internacionales entre los Estados Unidos y otras naciones ven en los contenidos cinematográficos y televisivos un objeto de atención particular.

Finalmente, cabe señalar una estrategia adicional: el gobierno americano dispuso en la tercera década del siglo pasado la coordinación de una nueva organización dedicada a recopilar información sobre los gustos cinematográficos de los consumidores internacionales país por país, región por región. De este modo el gobierno se encargaría de conseguir, organizar y distribuir esta información en beneficio de la maximización de los procedimientos de distribución de las películas de Hollywood. Esta información sería poco a poco introducida como material activo dentro del proceso mismo de producción cinematográfica.

De acuerdo con esta breve exposición de la relación Estado-Hollywood podemos asegurar una cosa: la labor del gobierno, que usualmente se entiende como la de protección del patrimonio cultural por medio de la gestión cultural, se pone en evidencia en este caso como mecanismo de administración comercial. En este sentido, como anticipábamos arriba, podemos entender la gestión cultural como acción industrial de Estado. Bien sea que hablemos del cine de carácter cultural patrocinado por el gobierno o de la producción industrial con financiación privada, en ambos casos el objeto cultural se comporta como mercancía. Se suele decir que las subvenciones y apoyos del Estado liberan, al menos en cierto punto, la producción cinematográfica de sus ataduras industriales; es decir, liberan al cine de los requerimientos narrativos y formales requeridos para los filmes y de la premeditada vida social de la película como mercancía. Sin embargo, esto es erróneo. Como señala Thomas Elsaesser a propósito del llamado nuevo cine alemán de los años setenta, podríamos decir que el escenario de la subvención estatal flota sobre el limbo de una contradicción: por un lado se les solicita a las películas defender una postura cinematográfica nacional, pero por otro lado se les pide que se comporten comercialmente al modo de un filme americano. Como si las decisiones estéticas, narrativas y formales no afectaran la vida social de las obras; es decir, como si romper con el canon formal hollywoodense en nombre de una cinematografía lo- 
cal no trajera consigo necesariamente alteraciones al nivel de la distribución y socialización de las obras (Elsaesser, 1989, p. 1). Esta contradicción es expresión del doble carácter de la mercancía cultural puesto en choque.

Así, visto desde la perspectiva de la producción, al modo en que Marx hace con la mercancía, la obra cinematográfica de carácter cultural o autoral desempeña un papel análogo al de la obra industrial, pero sobre ella recae una doble solicitud: primero, debe satisfacer las obligaciones de una obra industrialmente producida, esto es, debe seguir el modelo de comportamiento comercial impuesto por Hollywood; segundo, se le pide que actúe como objeto cultural, es decir, que contenga a la vez un cierto contenido estético y un cierto valor epistemológico de reconocimiento de lo otro o de la minoría. Como sea, sobre ella recae la exigencia de circular como circula cualquier película de James Cameron pero ocultando su procedencia tras la piel de cordero de la cultura, lo autoral o nacional. Como sugiere Andrew Higson, vista desde la perspectiva del consumo la obra cinematográfica nacional muestra un nuevo brillo. Ella se muestra así como una categoría económica de distribución y exhibición cinematográfica (Higson, 2002, p. 53). El cine cultural, entendido así, es un género más en las salas de exhibición. En consecuencia, sobre él recae un conjunto de expectativas administrativas, económicas y hasta ideológicas nacionalistas. El cine nacional es un objeto de gestión estatal que al aparecer como fenómeno cultural oculta su naturaleza y proyecta silenciosamente sobre las masas sus condicionamientos.

\section{Referencias}

Adorno, T. (2008). “Crítica de la cultura y sociedad”. En: Crítica de la cultura y sociedad I. Madrid: Akal.

Adorno, T. (2008b). "Resumen sobre la industria cultural”. En: Crítica de la cultura y la sociedad I. Madrid: Akal.

Arcos Martín, R. (2010). La lógica de la excepción cultural. Madrid: Akal.

Bourriaud, N. (2009). Radicante. Buenos Aires: Adriana Hidalgo. 
Carroll, N. (2002). Una filosofía del arte de masas. Madrid: La Balsa de la Medusa.

Castiñera de Dios, J. L. (2013). “Crítica de la gestión cultural pura”.En: Aportes para el debate,,23. Disponible en: http://www.asociacionag.org. ar/pdfaportes/23/07.pdf. Fecha de consulta: 2 de junio de 2013

Croft, S. (2002). "Reconceptualizing National Cinema/s”. En: Film and Nationalism. Rutgers: University Press.

Cuche, D. (2002). La noción de cultura en las ciencias sociales. Buenos Aires: Nueva Visión.

Elías, N. (2008). El proceso de la civilización. México D. F: Fondo de Cultura Económica.

Elseasser, T. (1989). "The Cultural Mode of Production in the New German Cinema”. Disponible en: http://www.thomas-elsaesser.com/ images/stories/pdf/elsaesser_the_author_of_the_film_cultural\%20mode\%20of\%20production.pdf. Fecha de consulta: 2 de junio de 2013

Flusser, V. (1990). Hacia una filosofía de la fotografía. México D. F.: Trillas.

Foster, H. (2002). El retorno de lo real. Vanguardias de fin de siglo. Madrid: Akal.

Higson, A. (2002). “The concept of National Cinema”. En: Film and Nationalism. Rutgers: University Press.

Horkheimer, M. y Adorno T. (1988). Dialéctica de la Ilustración. Buenos Aires: Sudamericana.

Maccari, B. y Montiel, P. (2012). Gestión cultural para el desarrollo. Buenos Aires: Ariel. 
Moreira, E. (2003). Gestión cultural: herramienta para la democratización de los consumos naturales. Buenos Aires: Longseller.

Naranjo, J. (ed.) (2006). Fotografía, antropología y colonialismo. Barcelona: Gustavo Gili.

Piault, M. H. (2002). Antropología y cine. Madrid: Cátedra.

Rancière,J. (2005). Sobre politicas estéticas. Barcelona: Universidad Autónoma.

Sempere, A. M. (2002). "La gestión cultural: singularidad profesional y perspectivas a futuro". En: Indigestión cultural, una cartografía de los procesos culturales contemporáneos. Buenos Aires: Ciccus.

Smith, A. (2010). "Images of the Nation". En: Cinema and Nation. Londres: Routledge.

Wallerstein, E. (2007). Abrir las ciencias sociales. México D. F.: Siglo XXI. 